\title{
Flood impact on critical linear infrastructures
}

\author{
Chiara Arrighi ${ }^{1}$, Maria Pregnolato ${ }^{2}$ and Fabio Castelli ${ }^{1}$ \\ ${ }^{1}$ University of Firenze, Department of Civil and Environmental Engineering, 3 Via di S. Marta, 50139, Firenze, Italy \\ ${ }^{2}$ University of Bristol, Department of Civil Engineering, Bristol, UK
}

\begin{abstract}
According to UNISDR, floods are the most frequent and damaging natural threat worldwide. Whereas the assessment of direct losses is well advanced, the evaluation of indirect impacts is less frequently applied. Indirect impacts are not due to the physical contact with flood water but result from the reduced performance of infrastructures. Linear critical infrastructures (such as roads and pipes) have an interconnected nature that may lead to failure propagation so that impacts extend far beyond the inundated areas and/or period. This work presents the analysis of two linear infrastructure systems, the water distribution system and the road network system. The evaluation of flood impact on the two networks is carried out for four scenarios, obtained by a coupled 1D-quasi 2D hydraulic model. Two methods are used for assessing the impacts on the water distribution system and on the road network, a Pressure-Driven Demand network model and a transport network disruption model respectively. The analysis is focused on the identification of: (i) impact metrics; (ii) vulnerable elements exposed to the flood; (iii) similarities and differences of the methodological aspects for the two networks. The study presents an application to the city of Florence (Italy).
\end{abstract}

\section{Introduction}

Infrastructures are exposed to floods all around the world. Critical ones, e.g. water-wastewater, transportation and energy systems, are considered so vital that their failure would have a debilitating effect on public health and economic security with repercussions on community resilience (Fekete, 2019; Tarani et al., 2019; Lhomme et al., 2013).

According to Koks et al. (2019), 7.5\% of road and rail infrastructures are exposed to a $1 / 100$-year flood event worldwide. Climate change could also aggravate impacts on road infrastructures in future (Pregnolato et al., 2017a; Evans et al., 2020). Infrastructures might suffer direct and indirect impacts. Direct impacts are due to the physical contact with floodwaters, indirect impacts occur outside the inundated area in space or time.

Although exposure of infrastructures to floods is quite basic to determine (Lyu et al., 2018), indirect impacts and cascade effects are widely considered as more significant to understand due to the interconnected nature of networks (Gil and Steinbach, 2008; Pant et al., 2016; Arrighi et al. 2017).

While the literature is well advanced in the assessment of direct flood impacts (Winter et al., 2016; Kellermann et al., 2016), indirect impacts and cascade effects are mostly addressed with complex conceptual frameworks (Fekete, 2019; Emanuelsson et al., 2014) and few applications to case studies (Arrighi et al. 2019; Pant et al., 2016). Most applications to transport network focus on the

\footnotetext{
a Corresponding author: chiara.arrighi@unifi.it
}

DOI 10.3311/FLOODRisk2020.6.3 identification of appropriate simplified vulnerability or risk indexes and metrics (Lyu et al., 2018; Balijepalli and Oppong 2014; Singh et al. 2018). A few works present combined flood-failure models to assess indirect impacts in time and space (Pant et al. 2016, Arrighi et al., 2017).

This work aims at (i) reconsidering the definition of affected people also including indirect impacts; (ii) identifying appropriate hazard and impact metrics for linear infrastructures with a focus on water supply systems (WSS) and road network; (iii) comparing assumptions and model features. Three different models are used for simulating inundation, water pressure in WSS and traffic disruption. The method is applied to the city of Florence (Italy).

\section{Method}

The method (Fig. 1) combines three different models: a flood hazard model, a road transport model and a WSS model. Reading the scheme of Fig. 1 top-down, the hazard model yields flood extent and maximum water depths for assigned probabilistic scenarios and allows for analysing the exposure of road segments and treatment or pumping facilities of the WSS.

Transport and WSS models support the analysis of vulnerability and the evaluation of indirect impacts. The combination of direct and indirect impacts obtained for each probabilistic scenario yields the risk to road network and WSS. In this work only indirect impacts have been evaluated. The potential collapse of bridges is neglected 
given the hydro-morphological characteristics of the river and catchment. The shutdown of lifting stations is not evaluated but assumed as a failure scenario.

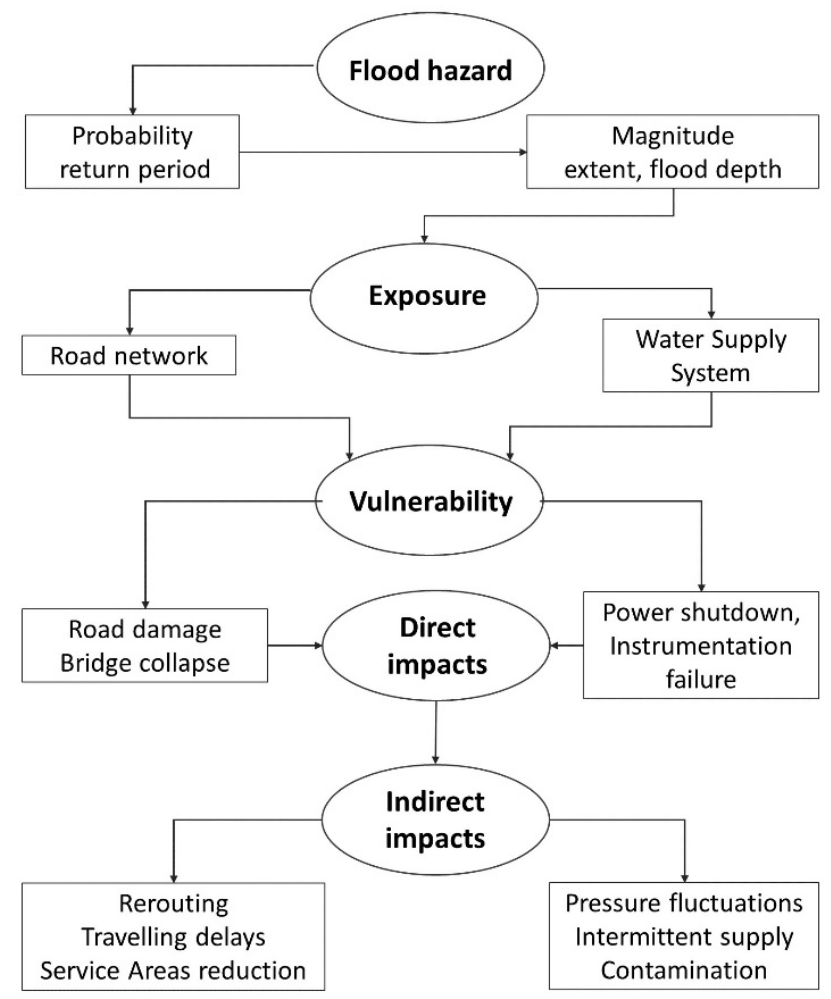

Figure 1. Methodological scheme for impact assessment

\subsection{Hazard and exposure analysis}

The hazard model is composed of two parts. The river is simulated with a 1D unsteady flow model and the urban flood-prone area is modelled as a system of interconnected quasi-2D storage cells. A Digital Surface Model (DSM) of $1 \mathrm{~m}$ resolution and $0.25 \mathrm{~m}$ vertical accuracy derived from LiDAR surveys is used for the detailed representation of the altimetry.

The flood propagation is computed through an implicit 1D finite-difference scheme of the unsteady flow equation (i.e. continuity and momentum conservation equations). The quasi-2D model for the floodplain consists of storage areas connected to the riverbanks through a set of lateral weirs, whose geometry is extracted from topographic survey. The quasi-2D module - governed by continuity and stage-storage relations - is activated when the bank overflow starts.

The details of the model construct and equations adopted in the HEC-RAS framework (for both 1D and quasi-2D modules) are described in Arrighi et al. (2013).

Exposure analysis consists in the intersection of inundated area and georeferenced elements, i.e. road segments or WSS nodes in QGIS.

The raster cell information (i.e. water depth) is then extracted over the line/point features and added as attribute using open plugins (e.g. Point Sampling Tool available for QGIS).

In this application hazard and exposure are evaluated for a medium probability scenario, i.e. a 200 -years recurrence interval event.

\subsection{WSS model}

The WSS model is based on EPANET libraries, which calculate time-varying pressures at the nodes of the network given a set of tank levels, pumps and demand patterns. When simulating strongly off-design networks, nodes featuring a reduced pressure are quite common, so that a pressure driven approach (PDD), not available in EPANET, is needed. In PDD models the demands at nodes are not attributed a priori, but their value depends on the current pressure at the considered node. The model used in this study assumes that each node can be in one of three states: (1) fully served when the node is able to withdraw its nominal demand; (2) partially served - when the node withdraws a reduced demand proportional to a fraction of nominal demand; (3) non-served when the node is unable to withdraw any water, yielding to null demand.

A MATLAB code has been implemented to run transient simulation while correctly using a PDD approach (Arrighi et al. 2017).

In the considered flood scenario (200-years recurrence interval) the model simulates how flood affects pumping/lifting stations and the consequent pressure reduction at nodes.

\subsection{Road network disruption model}

Changes in time and distance in commuters' journey due to inundation are analyzed by coupling a road network model with the hazard map, using a transport network disruption model developed by Pregnolato et al. (2016). This evaluation consists of calculating the disruption to network links as a result of the flooding simulation, comparing pre- and post-event travel times. Floodwater reduces travel speed of vehicles or stops traffic flows. Roads are commonly considered closed when the flood depth reaches $300 \mathrm{~mm}$, the depth at which a standard passenger's car is unable to operate; underpasses and elevated roads are considered as closed or completely functioning respectively. A disruption function, developed by Pregnolato et al. (2017b), relates water depth to safe driving speed. For the flooded scenarios, the network properties of a link (i.e. travelling speed) are modified according to this relationship, and traffic parameters recalculated for this perturbed state. Subsequently, journey travel time will increase in comparison with the baseline scenario.

\subsection{Risk metrics}

The definition of appropriate risk metrics is crucial to represent an objective measure and compare direct and indirect impacts. One of the critical objectives of this work is to identify metrics suitable both for road and WSS infrastructures. Two impact metrics are selected for this purpose, i.e. the length of the network and the population which undergoes some disruptions due to the loss of service.

The first metric can be easily converted into economic costs, e.g. the length of the WSS piping requiring flushing and disinfection, when costs per unit length are available. 


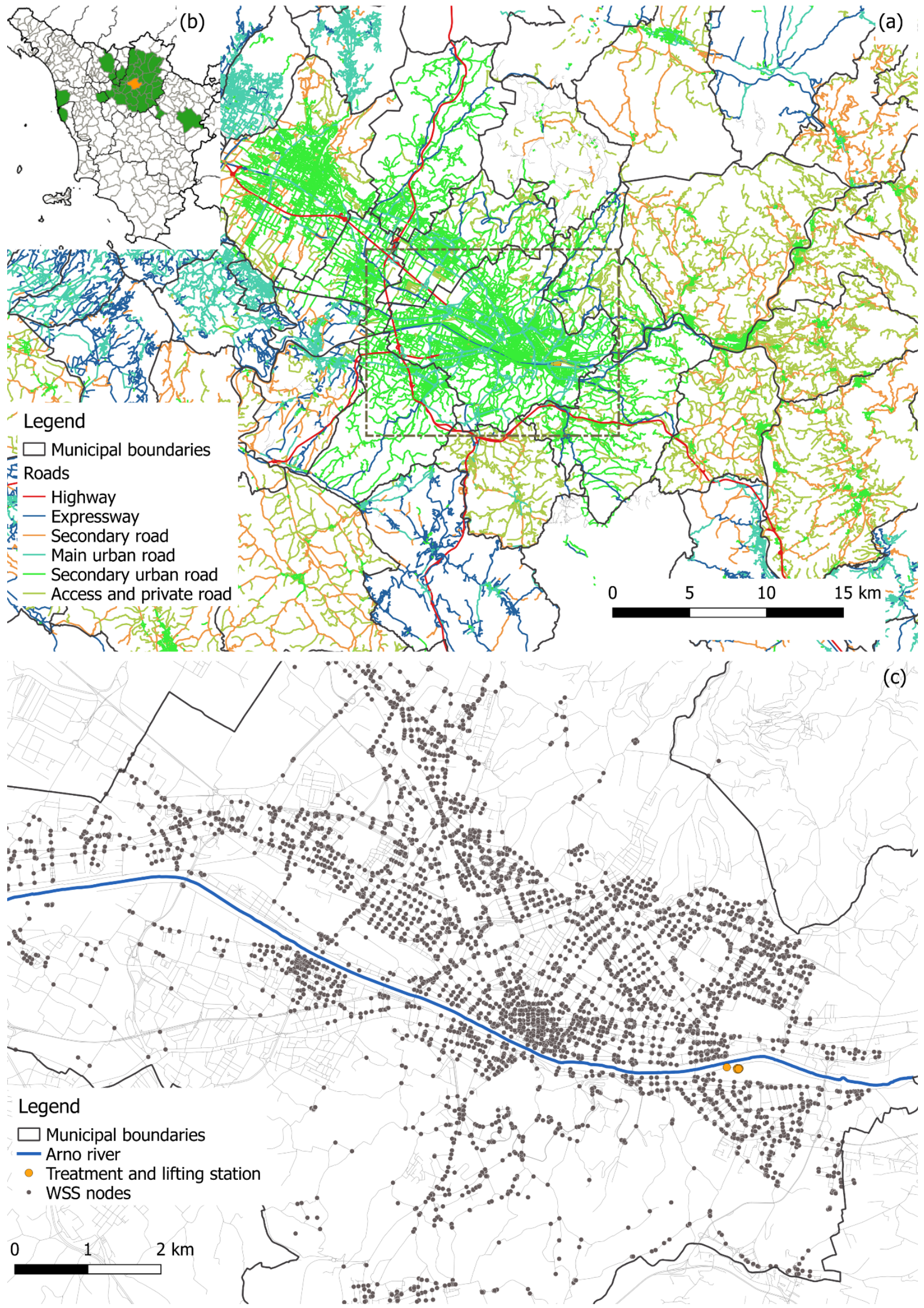

Figure 2. Presentation of study area, road network (a), commuters' basins (orange area is Florence) (Regione Toscana, 2015) (b), municipal WSS nodes and main treatment and lifting station (c).

${ }^{a}$ Corresponding author: chiara.arrighi@unifi.it

DOI 10.3311/FLOODRisk2020.6.3 
The second metric instead is more suitable to describe unmonetizable social costs. Table 1 summarizes the metrics adopted in this work.

\begin{tabular}{|c|c|c|}
\cline { 2 - 3 } \multicolumn{1}{c|}{} & Road network & WSS \\
\hline Hazard & \multicolumn{2}{|c|}{ Water depth (m) } \\
\hline Exposure & Road segments & WSS nodes \\
\hline Vulnerability & $\begin{array}{c}\text { Embankment, } \\
\text { elevated road, } \\
\text { underpass }\end{array}$ & $\begin{array}{c}\text { Pumping/lifting } \\
\text { station, treatment } \\
\text { plant }\end{array}$ \\
\hline Indirect impact & $\begin{array}{c}\text { Length of } \\
\text { impassable } \\
\text { roads (km) }\end{array}$ & $\begin{array}{c}\text { Length of } \\
\text { contaminated } \\
\text { pipework (km) }\end{array}$ \\
\cline { 2 - 3 } & $\begin{array}{c}\text { Delayed } \\
\text { commuters }\end{array}$ & $\begin{array}{c}\text { Population not } \\
\text { served }\end{array}$ \\
\hline
\end{tabular}

Table 1. Hazard, exposure, vulnerability and impact metrics for linear infrastructures.

\section{Case study}

The focus of this paper is Florence, Italy $\left(102 \mathrm{~km}^{2}\right.$ of extent). The area hosts 383000 inhabitants, with the highest population density concentrated in the city. The municipality has a long account of floods since the Middle Ages and is still prone to floods also for low recurrence interval (30-year return period). For such frequent events, only the lower-lying suburbs are inundated whereas more severe scenarios e.g. 200-years affect the whole city including its historic area.

The study area for the WSS model (Fig. 2, panel c) is the municipality of Florence. The municipal WSS features one main treatment facility with lifting station, 17 tanks, 619 $\mathrm{km}$ of pipework connected by 4863 nodes to supply drinking water for domestic and industrial use.

The study area for the road network model is the commuter catchment underpinned by the municipality of Florence $\left(3490 \mathrm{~km}^{2}\right)$ (Fig. 2, panel b). The municipality of Florence has the highest number of residents that daily commute and the biggest commuter catchment in Tuscany $(1,846,882$ people), with 43 municipalities of which 12 resides within the jurisdiction of other cities, i.e. Prato, Arezzo, Pistoia, Pisa, Livorno (Regione Toscana, 2015). The 79.5\% of commuting travels are within 30 minutes, the lowest percentage in the region, and the most common mean is private cars $(63 \%)$. The road network features more than 13 million $\mathrm{km}$ of road network and more than $600,000 \mathrm{~km}$ in the (simulated) hazard area.

\section{Results}

For the analysed 200-years recurrence interval scenario the failure of the lifting station of the WSS causes the reduction of pressures at nodes in the whole municipality, also outside the inundated area (Fig. 3). After six hours from the inundation of the lifting station, insufficient pressure affects $70 \%$ of the population (i.e. 268,100 people, three times the flooded population). Downstream neighborhoods and nodes served by local water tanks are affected later than city center. $428 \mathrm{~km}$ of pipework in the network, i.e. the $68 \%$, undergoes contamination risk six hours after the shutdown. For further detail on the temporal dynamics see Arrighi et al. (2017).

Similarly, for the WSS analysis, the road network is impacted by flooding within and beyond the inundated area. Around the $78 \%$ of roads in the hazard area is flooded, including 13,000 km of highways and 123,600 $\mathrm{km}$ of major roads (see Fig. 2). More than $10 \%$ of commuters are affected by an increase of their travelling time of $50 \%$. The travelling time of the commuters of 29 municipalities ( $>63 \%$ of all commuters, $>1$ million pp.) are increased by $>10 \%$. $\sim 10 \%$ of commuters $(>195,000$ pp.) are affected by an increase of their travelling time of $50 \%$; sensibly, the municipalities of these travelers are those in the hazard area (Signa, Campi Bisenzio and Poggio a Caiano). However, impact areas include also municipalities which are not contiguous to the hazard domain, in the North (e.g. Calenzano, > 132,500 pp., 30\% time increase) and municipalities in the South East (e.g. Bagno Ripoli, $>167,700, \sim 40 \%$ time increase).

\section{Discussion and conclusions}

The WSS and road transport system are two linear infrastructure systems, so they are comparable in terms of flood hazard and impact metrics. For example, the indirect impact is measured in length of network affected, i.e. closed or reduced speed segments for roads and pipework to be decontaminated, and in population disrupted by the loss of service. Although both metrics refer to population, the type of inconvenience is different. In fact, in the case of road network impact, delayed commuters experience difficulties in reaching their workplace, which can be somehow converted to monetary loss (e.g. salary reduction). In case of failure of the WSS the population not served might experience health issues especially for more vulnerable categories.

The exposure to flood is measured differently, since the road network features the length of the network, while the WSS system considers the number of nodes, with the crucial role of pumping nodes.

Moreover, the models used to assess in direct impacts differ in (i) scale of analysis, i.e. municipal vs regional; (ii) time-dependency on inundation dynamics; (iii) temporal spread of the disruption; (iv) system interaction with users. Regarding the second point, WSS disruption starts immediately after the flooding of the lifting station (next to the river) while the road network is flooded slowly before reaching the maximum depths. Regarding the fourth point, the WSS disruption temporal dynamics is also affected by users' behaviour that can be used to minimize losses to the infrastructure with appropriate emergency actions (Tarani et al., 2019)

Additional work could estimate the risk by performing the analysis to several probabilistic scenarios and also investigate how the two infrastructures recover after the event, e.g. the resilience of the two systems and their mutual connections. 




Figure 3. A detail of disrupted road network and WSS failure for a 200-years scenario in the municipality of Florence.

Further studies could include the physical impact to road elements (such as bridges), mitigation measure for the WSS and the interdependencies between the two systems, e.g. accessibility to pump station for repairs.

\section{References}

1. Arrighi, C. F. Tarani, E. Vicario and F. Castelli (2017) Flood impacts on a water distribution network. Nat. Hazards Earth Syst. Sci., 17, 2109-2123

2. Arrighi, C., M. Brugioni, F. Castelli, S. Franceschini and B. Mazzanti (2013) Urban micro-scale flood risk estimation with parsimonious hydraulic modelling and census data. Natural Hazards and Earth System Sciences 13(5),1375-1391

3. Arrighi, C., M. Pregnolato, R.J. Dawson, and F. Castelli (2019) Preparedness against mobility disruption by floods, Science of Total Environment, 654, 1010-1022

4. Balijepalli, C. and O. Oppong (2014) Measuring vulnerability of road network considering the extent of serviceability of critical road links in urban areas, J. of Transport Geography, 39, 145-155

5. Emanuelsson, M.A.E., N. McIntyre, C.F. Hunt, R. Mawle, J. Kitson and N. Voulvoulis (2014) Flood risk assessment for infrastructure networks, J. of Flood Risk Manag, 7, 31-41
6. Fekete, A. (2019) Critical infrastructure and flood resilience: cascading effects beyond water. Water, $\mathbf{6}$, e1370.

7. Gil, J. and P. Steinbach (2008) From flood risk to indirect flood impact: evaluation of street network performance for effective management, response and repair, WIT Transactions on Ecology and the Environment, 118, 335-345

8. Kellermann, P., C. Schoeneberger and A.H. Thieken (2016) Large-scale application of the flood damage model RAilway Infrastructure Loss (RAIL) Natural Hazards and Earth System Sciences, 16, pp. 23572371

9. Koks, E.E., J. Rozenberg, C. Zorn, M. Tariverdi, M. Vousdoukas, S.A. Fraser, J.W. Hall and S. Hallegatte (2019). A global multi-hazard risk analysis of road and railway infrastructure assets. Nat Commun 10, 2677

10. Lhomme, S., D. Serre, Y. Diab and R. Laganier (2013). Analyzing resilience of urban networks: a preliminary step towards more flood resilient cities, Nat. Hazards Earth Syst. Sci., 13, 221-230

11. Lyu, H.M., W.J. Sun, S.L. Shen and A. Arulrajah (2018). Flood risk assessment in metro systems of mega-cities using a GIS-based modeling approach, Sci. of Tot. En. 626, 1012-1025

12. Regione Toscana Ufficio Statistica (2015) Pendolarismo per motivi di lavoro o studio in Toscana, online last access [3-23-20] http://www.regione.toscana.it/documents/10180/675 
003/pendolarismo+report+DEF.pdf/246c955c-3dc94c2a-a15d-36334c151140

13. Sing, P., V.S.P. Sinha, A. Vijahni and N. Pahuja (2018). Vulnerability assessment of urban road network from urban flood, Int. J. of Dis. Risk Reduction, 28, 237-250

14. Pant, R., S. Thacker, J.W. Hall, D. Alderson and S. Barr (2018) Critical infrastructure impact assessment due to flood exposure, J. of Flood Risk Manag., 11, 22-33

15. Pregnolato, M., A. Ford, C. Robson, V. Glenis, S. Barr and R.J. Dawson (2016) Assessing urban strategies for reducing the impacts of extreme weather on infrastructure networks. Royal Soc. Open Sci. 3 (5), 115

16. Pregnolato, M., A. Ford, V. Glenis, S. Wilkinson and R.J. Dawson (2017a) Impact of Climate Change on Disruption to Urban Transport Networks from Pluvial Flooding, J. Infrastruct. Syst., 23(4), 1-13
17. Pregnolato, M., A. Ford, S.M. Wilkinson, and R.J. Dawson (2017b) The impact of flooding on road transport: a depth-disruption function. Transp. Res. D 55, 67-81

18. Tarani, F., C. Arrighi, L. Carnevali, F. Castelli and E. Vicario (2019) Flood resilience of a water distribution system, Advanced Sciences and Technologies for Security Applications, 177-194

19. Winter, M.G., B., Shearer, D. Palmer, D. Peeling, C. Harmer and J. Sharpe (2016) The Economic Impact of Landslides and Floods on the Road Network, Procedia Engineering, 143, 1425-1434.

20. Yin, J., Y. Dapeng, Z. Yin, M. Liu and Q. He (2016). Evaluating the impact and risk of pluvial flash flood on intra-urban road network: A case study in the city center of Shanghai, China, J. of Hydrology, 537, 138145 